\title{
Establishing the Impact of Area Studies Collections and Exploring Opportunities for Collaborative Collecting
}

\section{Mara L. Thacker, Thomas H. Teper, Joseph Lenkart, and Esra Çeltek Coşkun}

This study examines the use of area studies materials by assessing five years of Interlibrary Loan (ILL) lending data and local circulation data from a single research library. It seeks to lay groundwork for future explorations into the implementation of a robust cooperative collection development model for area studies at the national level, with analysis demonstrating that existing ILL programs support scholars from research institutions far beyond their owning institution. They can do so with minimal adverse impact on the local community of scholars at a typical top-tier research library. This case study also investigates the similarities and differences between lending patterns of Less Commonly Taught Language (LCTL) materials and non-domestic area studies titles that are authored in commonly taught languages. The authors conclude with an argument that communities of institutions could develop highly structured cooperative collection building efforts in the area studies that would permit them to redirect resources strategically, collecting area studies materials both more deeply across the community and with a greater emphasis on primary source materials.

Mara L. Thacker (mthacker@illinois .edu) is the South Asian Studies Librarian Global Popular Culture Librarian, University of Illinois at UrbanaChampaign. Thomas H. Teper (tteper@ illinois.edu) is Associate Dean of Libraries for Collections and Technical Services, University of Illinois at UrbanaChampaign. Joseph James Lenkart (lenkart@illinois.edu) is the Manager of Slavic Reference Service and International Reference Librarian, University of Illinois at Urbana-Champaign. Esra Celtek Coskun (coskun@illinois.edu) is Collections Analysis and Planning Specialist, University of Illinois at UrbanaChampaign.

Manuscript submitted January 5, 2018; returned to authors for revision August 15, 2018; revised manuscript submitted August 31, 2018; accepted for publication September 24, 2018. rea studies units at research libraries play a critical role in supporting net$\mathbf{A}_{\text {works of scholarly communities through resource sharing and cooperative }}$ acquisitions of materials from around the world. Understanding the dynamics between institutions, resource sharing, and collection building remains vital to research libraries and international and area studies programs in higher education.

Area studies collections comprise interdisciplinary materials pertaining to particular geographical or cultural regions. The division of regions and countries in area studies collections reflect the national priorities set forth by the office of International and Foreign Language Education (IFLE) at the US Department of Education. The areas can be divided as follows: Africa, Central Asia/Inner Asia, East Asia, Middle East, Russia/East Europe, South Asia, Southeast Asia and the Pacific Islands, and Western Hemisphere (Canada, Mexico, Caribbean, and Central/South America). Library collections for these areas may be scoped based on whether the content is about the area, published in the area, or is in the area's 
vernacular language. The most complicated of these for US libraries to collect are non-English, vernacular language materials. Vernacular language collections in area studies require specialized knowledge to build and, therefore, often emerge as the focal point of discussions about area studies collections. Yet, for regions with a colonial legacy, the colonial language of governance often persists as a primary language of both scholarship and governance. Therefore, it is important that research about area studies collections use country of imprint as one parameter to identify area studies materials, rather than simply relying on the language of the materials. This study embraces that outlook and analyzes the impact of area studies collections using one research library's ILL lending data as a case study.

Presently, academic libraries seek opportunities to more effectively manage and share resources, enhance programs and services, and navigate a changing scholarly communications environment. Although there is a long history of collaboration among libraries, many librarians channeled concerns expressed by their local constituents, objecting to calls for broader, systematic collaboration in collection development out of fear that local needs could not be adequately addressed by broad collection policies and distributed collections. That concern is ebbing, as "at scale" commercial solutions aggregate content for sales and expedited delivery. The success of these models led to ambitious non-profit solutions that seek to tackle challenges libraries face in combining, sharing, preserving, and delivering collections. Taken together, this softening opposition and the successes already experienced are leading toward a greater desire among librarians to realize the "library of everything."

As the desire to build a library of everything grows, the motivation of individual libraries to build a "collective collection" is becoming a reality. This desire is driven by multiple factors. As Levine-Clark noted, the changing nature of institutional funding challenges old collecting models. Similarly, Walter and Kaufman highlighted the refocusing of library missions from collection-centric to service-centric as a factor in motivating change. Similarly, works focused on rethinking resource sharing efforts, the availability of more robust data about our collections, and the prospect of retaining a cohesive-if distributed-corpus all lend credence to the notion that libraries should deliver "everything" from a collective collection. ${ }^{2}$

Long a mainstay of the academic library service model, resource sharing is taking on new dimensions as research libraries develop cooperative frameworks upon which collection development programs can be built. The collaborative efforts that emanated from the early twentieth century often stand as component parts of a mosaic of agreements that allowed participants to serve their local constituencies. These initial resource sharing agreements were largely subsumed by regional consortial arrangements such as the Triangle Research Libraries Network (founded in 1977 upon the expansion of an initial collaboration dating to 1933) and other arrangements in which the fundamental ownership model was not changed. ${ }^{3}$ In these models, member institutions owned the volumes they acquired and shared them with other member institutions. The 1950s witnessed the advent of a new collective model with the creation of the Midwest Inter-Library Consortium (MILC). As the precursor to the Center for Research Libraries (CRL), the MILC's ten founding member institutions and financial underwriter, the Carnegie Corporation, recognized that less commonly used items could be cooperatively acquired, preserved, and shared more cost effectively through a single agency than through individual members. ${ }^{4}$ CRL's model served as an early demonstration of the value that "at scale" solutions brought to bear in addressing common challenges among research libraries.

The challenges that CRL's early operational model addressed for member institutions ring true today, including the impact of a changing educational environment on space, personnel, and financial resources. During the postwar expansion of higher education, institutional leaders realized that space and resources would not permit them to collect everything. Today, changes in the educational environment are redefining the roles that libraries take in serving both faculty and students, compelling them to adopt a more service-oriented posture. Furthermore, the relative ease with which institutions can collect and analyze data about their collections is compelling institutions to rethink how those collections are built and serviced. The fundamental question that many librarians face regarding these changes with the constituencies they serve is whether shared resources held remotely will be sufficient to meet local needs.

This paper continues the authors' work published in College \& Research Libraries. ${ }^{5}$ In both the previous and present study, the authors analyzed five years of ILL lending data, focusing on successful fulfillment of requests for area studies materials received from other institutions. While the previous study identified area studies materials based on language by looking at ILL requests for materials published in languages other than the more commonly taught English, Spanish, French, and German, this study is more expansive. In the present study, the authors identify area studies materials by place of publication. This ensures that countries and regions with a rich tradition of publishing materials in the more commonly taught languages are not underrepresented in terms of their impact. By analyzing these data, the authors drew conclusions about the usage of area studies materials by scholars beyond their home institutions and how such usage might influence the development of more formal initiatives in cooperative collection 
development, collective collections, and shared print management. They examined collection use within the context of the types of institutions borrowing the materials via ILL to measure the impact for researchers outside of research libraries. They also analyzed the regional impact of area studies materials by reviewing locations of requesting institutions. The present study provides further evidence that research libraries could invest more resources into developing enhanced models of cooperative collecting in area studies while still meeting most local constituent needs.

\section{Literature Review}

In the last ten years, the subject of area studies collections and their overall management gained considerable momentum among libraries, academic institutions, consortia, and other non-governmental agencies. This renewed interest produced, in addition to scholarly publications, a series of workshops and conferences designed to identify strategic areas for cooperation, collaboration, and resource sharing. In these settings, formal presentations and research papers introduced new ideas for cooperatively managing area studies collections and strengthening national resource sharing networks. A few notable works that focused exclusively on area studies include: International and Area Studies Collections in 21st Century Libraries; Collaboration, Advocacy, and Recruitment: Area and International Studies Librarianship Workshop; NRC Conference: Demonstrating the Impact of National Resource Centers; and International and Area Studies Collections in the 21st Century. ${ }^{6}$ Many of these discussions highlighted strategies for collective action on a number of fronts to ensure that area studies information networks flourish in the twenty-first century.

Research on the use of international and area studies materials is limited when viewed within the context of a defined network of borrowing institutions and the set parameters of this study. Although there is considerable scholarly literature on examining interlibrary loan (ILL) operations and extensive research on the development, history, and role of international and area studies collections, limited research exists that specifically draws conclusions about the role of interlibrary lending in serving the needs of scholars requiring access to area studies collections. However, threads can be drawn between disparate studies that lead to solid conclusions.

Mak's 2011 study, which examined thirty-five years of resource sharing data among American Research Libraries (ARL) in the United States, tracked the growth of resource sharing among institutions and identified key ingredients for sustaining a "technically robust" national resource sharing infrastructure. ${ }^{7}$ Similarly, Juergens and Prather reported OCLC-based ILL patterns among institutions. ${ }^{8}$ This study provides an invaluable snapshot of ILL activity at the institutional, state, and regional levels. Additionally, Juergens and Prather examined an unidentified ARL library's borrowing and lending behavior during fiscal years 1992 and 1993 to highlight "how resource sharing has evolved into an essential element in library collection management." A topic addressed in several presentations at the aforementioned workshops, this is also echoed by Jakubs in her 2015 study "Trust Me: The Keys to Success in Cooperative Collections Ventures." ${ }^{\prime 10}$ As she states:

The strategy of building on strength, recognizing de facto lead institutions, and encouraging the deepening of locally strong collections, has made it possible for some libraries to stop collecting in areas that are supported elsewhere . . . and to invest the funds in more specialized materials. The ultimate result has been the expansion of the 'commons,' the larger universe of research resources available to all researchers. ${ }^{11}$

Mak, Juergens and Prather, and Jakubs point to the requirements for a strong lending network, the role of such networks in major research libraries, the initial impact of that on cooperative collections work, and, in some cases, where this has been explicitly successful in relation to collecting and serving area studies materials.

Taken a step further, Jackson et al.s 2006 study provides a useful analysis of global collecting patterns within ARL institutions. ${ }^{12}$ This research shows both the distribution of publications from outside of North America within ARL member institutions and the level of overlap, concluding that there is much less overlap of publications from outside of North America. Williams and Woolwine's study "Interlibrary Loan in the United States: Analysis of Academic Libraries in a Digital Age" examined ILL statistics for all materials from 1997 to 2008. This extensive study on resource sharing in American academic libraries analyzed two primary elements: the effect of full-text databases and the size of print collections on ILL rates and activity. ${ }^{13}$

Although librarians and scholars express caution about remote collections, two frequently cited studies support the thesis that cooperatively developed collections could serve broad networks of libraries. The usage patterns in these networks are fluid enough that collecting activities could shift toward both the most heavily used and least commonly held items without diminishing network-wide service. The first study, O'Neill and Gammon's "Building Collections Cooperatively: Analysis of Collection Use in the OhioLINK Library Consortium," demonstrated that statewide networks may over-acquire to serve their user populations and touched on the notion that opportunities exist for Less Commonly Thought Languages (LCTL) collections to serve 
broader populations. ${ }^{14}$ While multiple holdings benefitted users in some cases, usage indicated that significant bodies of material within the OhioLINK network did not require duplicate holdings to serve the membership. O'Neill and Gammon concluded that a typical book circulated 0.109 times per year. They also concluded that foreign language items only circulated an average of 0.019 times per year, supporting the notion that both less commonly held and less frequently used materials could be effectively shared across a network of academic libraries. ${ }^{15}$ Presumably, this could be accomplished without critically hampering local services.

The conclusions of O'Neill and Gammon's results were tested and largely confirmed by Wiley et al.'s 2011 examination of the usage of domestically produced monographs among the Consortium of Academic and Research Libraries in Illinois (CARLI). ${ }^{16}$ Both studies reinforce beliefs espoused by pioneers in international and area studies collecting such as Hazen and Spohrer that the longtail of our holdings, those items infrequently used and not needed for regular on-site reference-type consultation, could effectively serve broader populations of scholars if resource sharing networks existed to facilitate access and usage. ${ }^{17}$ This conclusion was tested in a live setting by Columbia and Cornell University Libraries as they sought to fully integrate services and collections for Slavic, East European, and Eurasian Studies (SEEES) across the two universities' libraries. As detailed by Davis in "2CUL Slavic: The View So Far," the integration concluded its sixth year of serving the needs of scholars at the two Ivy League universities in $2016 .{ }^{18}$ A strong network, a history of collaboration, and a common goal allowed the two universities to reduce duplication, share resources, and collect more deeply across the partnership. Indeed, Davis' conclusions echoed those of Jakubs related to trust as a key component to successful collaboration, and Lenkart et al. related to the potential for a broader network to similarly serve the needs of scholars in need of access to area studies materials.

While lending data may support networked collecting and conclusions about 2CUL SEEES's success may support similar conclusions, the decision to shape local collection development practices by using ILL data concerns some librarians. For example, Leykam's study "Exploring Interlibrary Loan Usage Patterns and Liaison Activities: The Experience at a US University" cautions against using ILL statistics for collection development decisions, as they may reflect the interests of individual users and not broader institutional needs. ${ }^{19}$ While this is true, in the realm of international and area studies collecting, the concept of the collective collection long permeated discussions and planning among scholars, subject specialists, and administrators. Recently, Bailey-Hainer et al. suggested new collaborative models and proposed partnerships on collection development, chronicling innovative strategies to promote interlibrary lending among institutions from around the world. ${ }^{20}$

As cautioned above, reliance on interlibrary lending statistics and bibliographic data listed in ILL forms as the basis for comparative analysis is problematic if no attention is given to actual publishing patterns. National trends and publishing in languages covered in statistical yearbooks and national bibliographies provide additional sources for comparative analysis. ${ }^{21}$ Using a key set of indicators, the International Publishers Association tracks global trends in publishing in its annual reports, which provide supplemental coverage for publishing analysis. ${ }^{22}$ Moreover, the German Book Office's report on publishing in India and Atbach's study on publishing in national languages reveal local dynamics associated with the use of national and regional languages. ${ }^{23}$

\section{Research Questions}

The overarching question behind this investigation was: given the long-established collaboration in area studies collecting, how can one determine whether international and area studies collections are serving their intended purpose? Area studies collections are meant to serve both local scholars who need to incorporate international perspectives and materials into their research and also contribute to the national collection, which may serve anyone doing international and area studies research in the United States. Given the history of collaboration among research libraries in collecting international resources, this question requires that librarians and administrators consider both local usage and the impact those collections may have across institutions and geographic boundaries. Specifically, the authors sought to determine:

1. What types of libraries borrow materials from the University of Illinois at Urbana-Champaign's area studies collection?

2. How are the benefits of lending area studies materials from the University of Illinois at Urbana-Champaign to institutions dispersed across different geographic regions of the United States?

3. Does the impact of materials from the University of Illinois at Urbana-Champaign's area studies collections vary when using the country of publication to identify materials rather than the language of publication?

4. How does demand for materials on a particular subject change based on language or country of publication of those materials?

5. Is there any correlation between local circulation of area studies materials and lending of those same materials outside of the University of Illinois at Urbana-Champaign? 
6. Do rarely held materials experience the same demand as widely held materials in terms of both local circulation and ILL requests?

7. Can low-use unique collections serve broadly distributed populations of users?

\section{Method}

After receiving approval from the local Institutional Review Board, the team reviewed data generated and made available to them by the library's Interlibrary Loan and Document Delivery Unit (ILL/DD). It consisted of monthly lending reports spanning 2009 through 2013. The ILL/DD unit removed any personally identifying information prior to delivering the data.

The team merged the monthly reports to create a single database containing all lending records for the five years covered. This database included records for 177,366 transactions, which altogether contained 105,849 unique titles. With the help of a student worker, records indicative of renewals were removed to ensure that the demand for a particular item did not appear inflated. The student also removed ILL lending records for which critical information like imprint city or OCLC number were missing, as the absence of this data point eliminated the ability to firmly identify publication location and crosswalk it to a region. The data was then further processed in a number of ways as explained below.

The team created a new field in the spreadsheet and manually entered "Imprint Country" information based on the "Imprint City" field in the database. Region names were also assigned to these countries based on the Title VI Region List. To assign regions to borrowing institutions within the United States, the team used the US Census Bureau's Region and Division list-the Southern, North Eastern, Western, and Midwestern United States. The research team also added "Library Type" information (academic, public, corporate, etc.) based on the categories listed by OCLC. ${ }^{24}$ Finally, OCLC holdings counts showing number of copies available from other OCLC member institutions for the same item were added to the database. Local circulation counts for the same period were added for each item.

The authors made no attempt to deduplicate the titles associated with the OCLC numbers recorded in the ILL data against alternate bibliographic records in OCLC that might represent the same item, meaning that there could have been local circulation associated with the same title cataloged in a variant manner. Additionally, the authors did not clean up volume and issue information associated with journal requests or identify item linking errors in local lending transactions. The data in these particular requests often include significant inaccuracies, particularly with volume information. However, disregarding this information shifts the entire loan request to a single bibliographic record, making comparisons between monograph and journal lending inexact. Consequently, the subsequent analysis often differentiates between lending data for monographs, journals, or both. ${ }^{25}$

\section{Results \\ Lending by Institution Type}

Through analyzing the borrowing activities by institutions according to the OCLC institution type and attributes that those institutions self-assigned when creating OCLC institutional accounts, the results show that primary beneficiaries of outgoing lending transactions consisted of institutions coded as "Academic" libraries, comprising 57.32 percent of borrowing institutions and "Major Academic Research" libraries, which accounted for 28.40 percent of lending transactions. The distinction between these categories is that "Major Academic Research" libraries connote doctoral granting universities, whereas an "Academic" institution is a general phrase that can include community colleges, baccalaureate colleges, and colleges with limited graduate or professional programs. Their combined total of 85.73 percent of lending is not unexpected given that such institutions serve similarly minded patron groups that use local collections and well-established ILL services to meet their research needs.

It is not just academic libraries that benefit from lending activities. "Public" libraries account for 8.87 percent of lending, "Corporate" libraries account for 1.22 percent of lending transactions, and "Federal Government" libraries for 1.15 percent. Since many area collections receive some federal funding through the Title VI National Resource Centers Program of the US Department of Education, it is important to highlight this tangible return on federal investment. All remaining institution types combined account for only 3.03 percent of lending.

In addition to which types of institutions submit the most borrowing requests, the authors further analyzed the data to determine whether differences existed in the subject areas of materials borrowed by the various institution types. As the table below illustrates, two subjects are particularly popular across institutional types—science and language and literature. These subjects appeared among the two most borrowed subject areas for five different institution types. For "Law Libraries" and "Medical Libraries," it is not surprising that law and medicine respectively ranked among the most borrowed subjects. There were only two subject areas that could be considered outliers: 
Table 1. ILL Lending by Library Type

\begin{tabular}{lcc|}
\hline Library Type & ILL Lending & \% of Total \\
\hline Academic & 97,389 & $57.32 \%$ \\
\hline Major Academic Research & 48,255 & $28.40 \%$ \\
\hline Public & 15,064 & $8.87 \%$ \\
\hline Corporate & 2,080 & $1.22 \%$ \\
\hline Federal/National Government & 1,955 & $1.15 \%$ \\
\hline Junior, Community, Technical Colleges & 1,248 & $0.73 \%$ \\
\hline Law Libraries & 906 & $0.53 \%$ \\
\hline Theological & 670 & $0.39 \%$ \\
\hline Schools Below College Level & 505 & $0.30 \%$ \\
\hline State or Municipal Governments & 482 & $0.28 \%$ \\
\hline Association/Foundation & 473 & $0.28 \%$ \\
\hline State Library & 471 & $0.28 \%$ \\
\hline Other & 205 & $0.12 \%$ \\
\hline Medical & 176 & $0.10 \%$ \\
\hline Vendor & 9 & $0.01 \%$ \\
\hline Art Music History & 2 & $0.00 \%$ \\
\hline Total & 169,890 & $99.98 \%$ \\
\hline
\end{tabular}

Note: Percentages do not add up to $100 \%$ because of rounding.

(1) agriculture was the second most popular subject for materials borrowed by state and municipal governments and (2) fine arts was the second most borrowed subject area for foundations and associations-perhaps reflecting the association of museums and museum libraries with various other non-profit operating models.

\section{Regional Impact Across the United States}

As noted, "Academic" and "Major Academic Research" predominate among borrowing institutions. These borrowing institutions are scattered across the country, yet the intensity of borrowing is heavily influenced by two factors: consortial affiliation and the presence of Title VI national resource centers. As might be expected given the University of Illinois's membership in the Big Ten Academic Alliance (BTAA), the majority of outgoing transactions went to institutions within the consortia, even when lending activity within the state of Illinois is excluded. When Illinois is excluded, the states with the highest percentage of lending transactions were: Michigan (14 percent), Indiana (9 percent), Wisconsin (8 percent), Pennsylvania ( 7 percent), and Minnesota $(7$ percent). These contributed to an overall lending rate of 59 percent to states with BTAA member institutions. Beyond the BTAA member institutions, the states that borrowed the most materials were California (5 percent), Texas (4 percent), New York (4 percent), North Carolina (3 percent), Missouri (3 percent), and Massachusetts ( 3 percent). The remaining states borrowed less than 3 percent each and, combined, represent under a quarter of total lending.

\section{Country of Imprint versus Language of Publication}

The juxtaposition of lending patterns for area studies materials that are in LCTLs and area studies materials identified as such based on country of imprint loomed large in the authors' original motivation for this study. The data shows that for some areas excluding Commonly Taught Language Materials (defined as English, French, German, Italian, and Spanish) diminished the perceived impact of these collections.

For example, one may consider materials from Latin America, which were largely excluded from the original study because of two factors. First, Spanish is a Commonly Taught Language (CTL). Second, the difficulty of disambiguating whether Portuguese publications, despite the language's status as a LCTL, were from Europe, Brazil, or other former Portuguese colonies located outside of Latin America made their inclusion based on language impossible. Using the metrics resulting from the exclusion of these languages, Latin American materials did not comprise a full percentage point of overall lending when the key marker was LCTL. Using the country of imprint as a filter, however, results in Latin American materials comprising 4 percent of total lending.

In another example, figure 3 demonstrates that English language publications from South Asian countries comprise a greater percentage of the total lending than any region outside of the United States, the United Kingdom, and Western Europe. Overall, South Asian materials published in English account for nearly 3 percent of the total lending in English.

Materials in vernacular South Asian languages account for only 0.2 percent of total lending. Yet, when place of publication rather than language is considered, South Asian imprint materials account for 2.2 percent of total lending. Should this information be used to influence funding, the incompleteness of the language-only model should be apparent when colonial languages continue to predominate in the publishing of particular regions. Table 3 illustrates the differences in lending by publication region versus by language for all world regions. It should be noted that Portuguese and CTLs like English, French, and German are their own language category to draw distinctions between materials published in CTLs in the United States and Western Europe and materials in those languages published elsewhere, particularly in formally colonized countries. Otherwise, languages are presented as regional language groups. In the Latin American and Caribbean language 


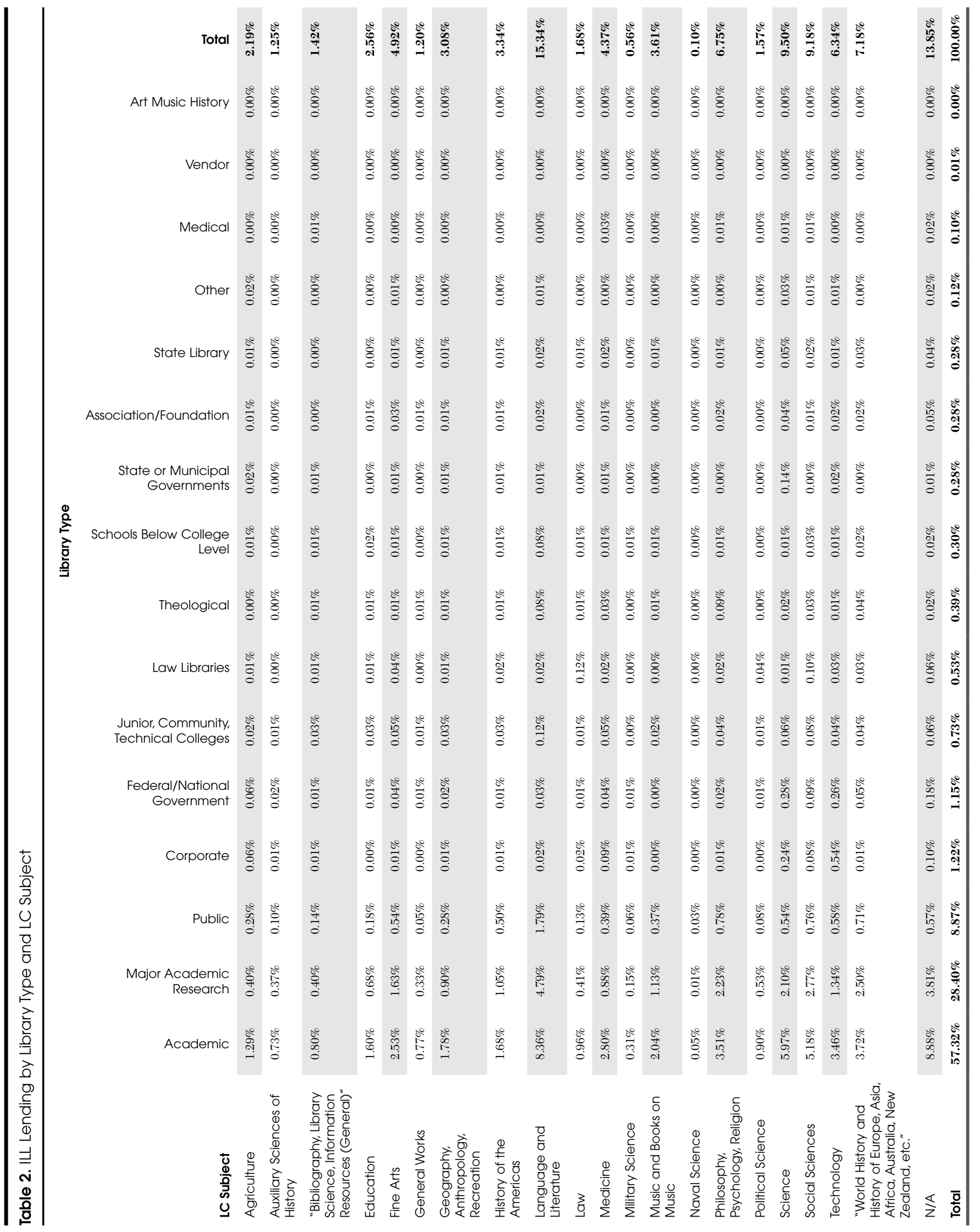




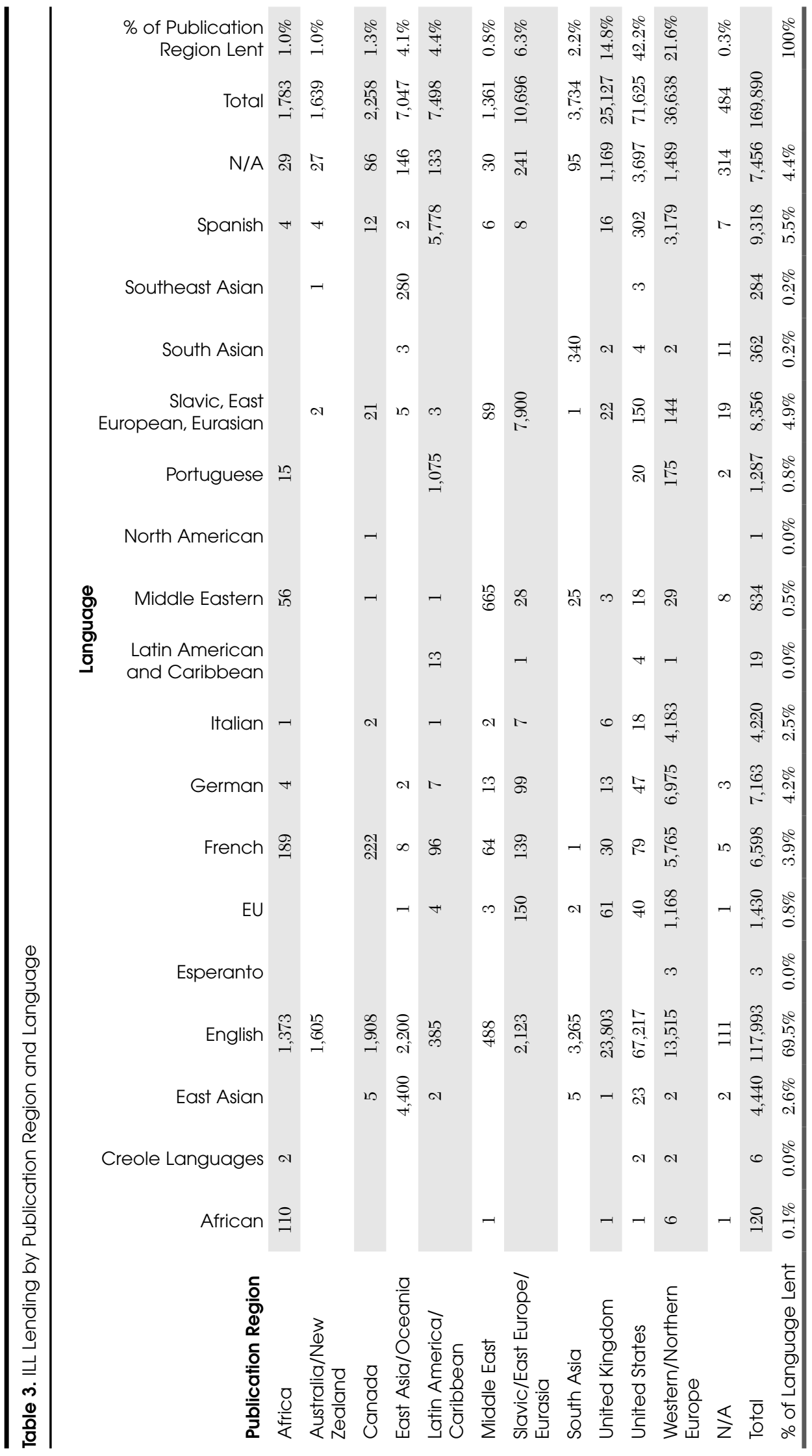

grouping this would therefore exclude Spanish and Portuguese and instead describe languages like Nahautl, Quechua, Mayan languages, and others.

\section{Lending by Subject Area}

As defined by Library of Congress Subject Headings, the most popular subject areas lent from all regions, including the United States, and irrespective of language of publication were: (1) Language and literature; (2) Science; (3) Social sciences; (4) World history and history of Europe, Asia, Africa, Australia, New Zealand, etc.; (5) Philosophy, psychology, and religion; and (6) Technology. Each of these areas accounted for more than ten thousand ILL transactions for the five-year period.

Among the geographic regions, the authors identified the top three categories per area. While all regions focused largely on the same categories, they were not always in the same order, and a few exceptions appeared. Africa and Australia/New Zealand were the only regions in which "World history and the history of Europe Asia, Africa, Australia, New Zealand, etc.", appeared as the most popular subject area. Furthermore, Australia/New Zealand had a tie between the "World history ..." category and "Science" as the most popular. "Science" was also in the top three for Slavic/East Europe/Eurasia and Canada. For materials with a US imprint, "Technology" ranked as the third most popular subject. The difference in popularity of subjects for materials from different regions may reflect research and publication trends within institutions in those countries. Institutions in a geographic area 


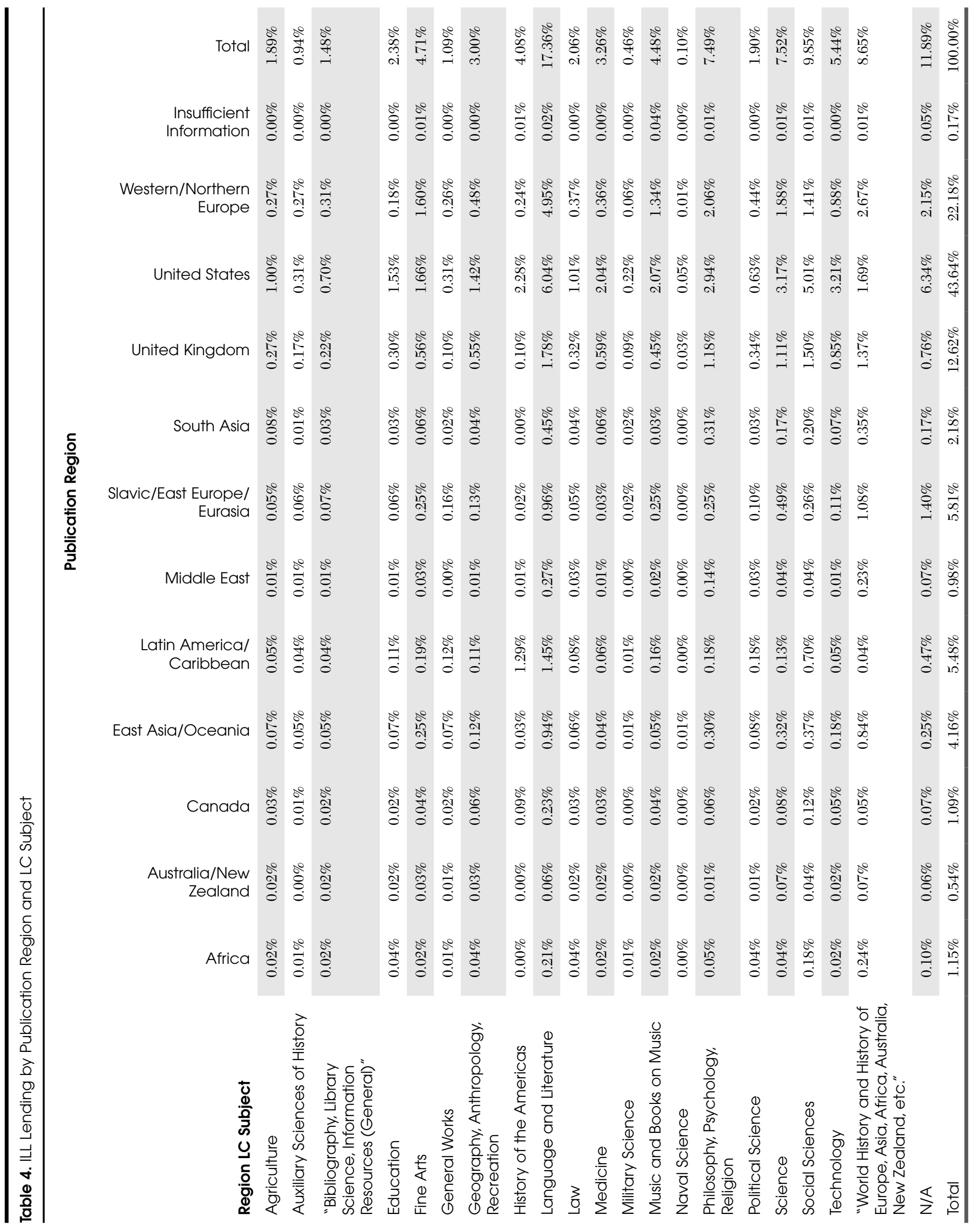




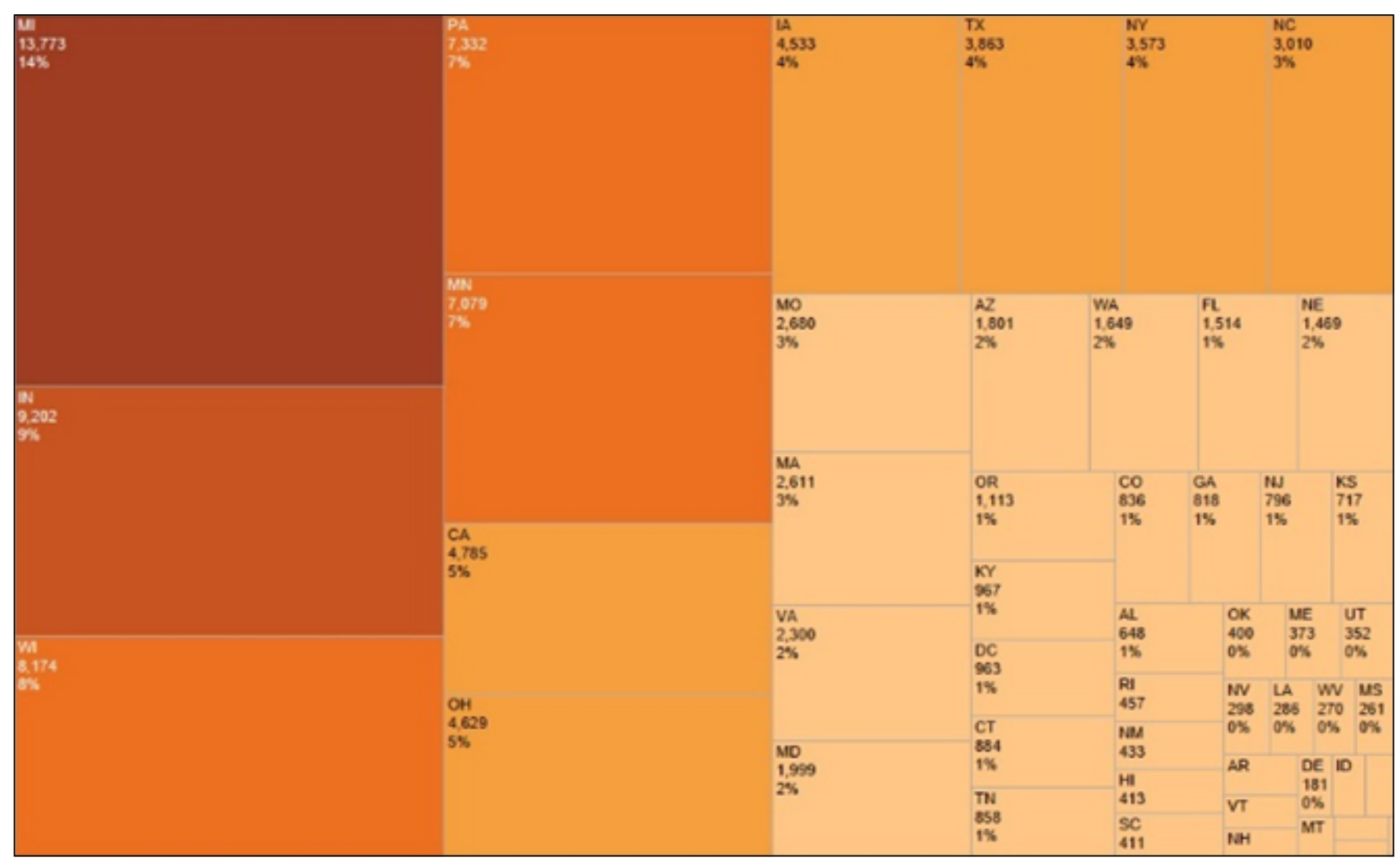

Figure 1. ILL Lending by US State

that emphasizes or values particular subjects may therefore produce greater quantities of published material on those subjects than institutions in other geographic areas with different values.

When removing country of imprint and considering the popularity of different subjects based on English versus non-English materials for all materials lent to countries other than the United States, it is interesting to note which materials experience greater demand in vernacular languages. Regarding raw numbers from the dataset of lent materials, the subjects in which non-English materials circulated more than English materials were: (1) Language and literature; (2) World history and history of Europe, Asia, Africa, Australia, New Zealand, etc.; (3) Philosophy, psychology, religion; (4) Fine arts; (5) Music and books on music; (6) History of the Americas; (7) Political science; and (8) General works. For all other categories, Englishlanguage materials were the most popular. This may reflect the languages that currently dominate particular fields such as the STEM (science, technology, engineering, and math) disciplines, or it may reflect the relative scarcity of resources from particular regions combined with the tendency among the humanistic disciplines to draw upon a broader array of source materials.

\section{Local Circulation versus Lending}

In comparing the local demand for an individual title to the demand for a title from borrowing institutions, the authors compared local circulation statistics to ILL statistics and further analyzed the results by examining the number of OCLC holdings. The data demonstrates that the demand for materials via ILL mirrors the demand for those same titles in local circulation. Interestingly, the two categories that circulate the most both locally and via ILL are the most and least frequently held items. More rarely held materials, for which only one to ten copies are available in OCLC, account for 15.6 percent of ILL transactions and 16.8 percent of local circulation. The most commonly held materials, with ninety-one or more copies available in OCLC, account for about 42 percent of both ILL and local circulation.

This result can be interpreted in various ways. First, it demonstrates that long-tail collections do meet service needs at institutions across the nation. The caveat is the difficultly in knowing whether there are situations in which rarely held materials are rendered inaccessible locally while they are being lent to an outside institution, or external scholars who are unable to borrow the materials because 


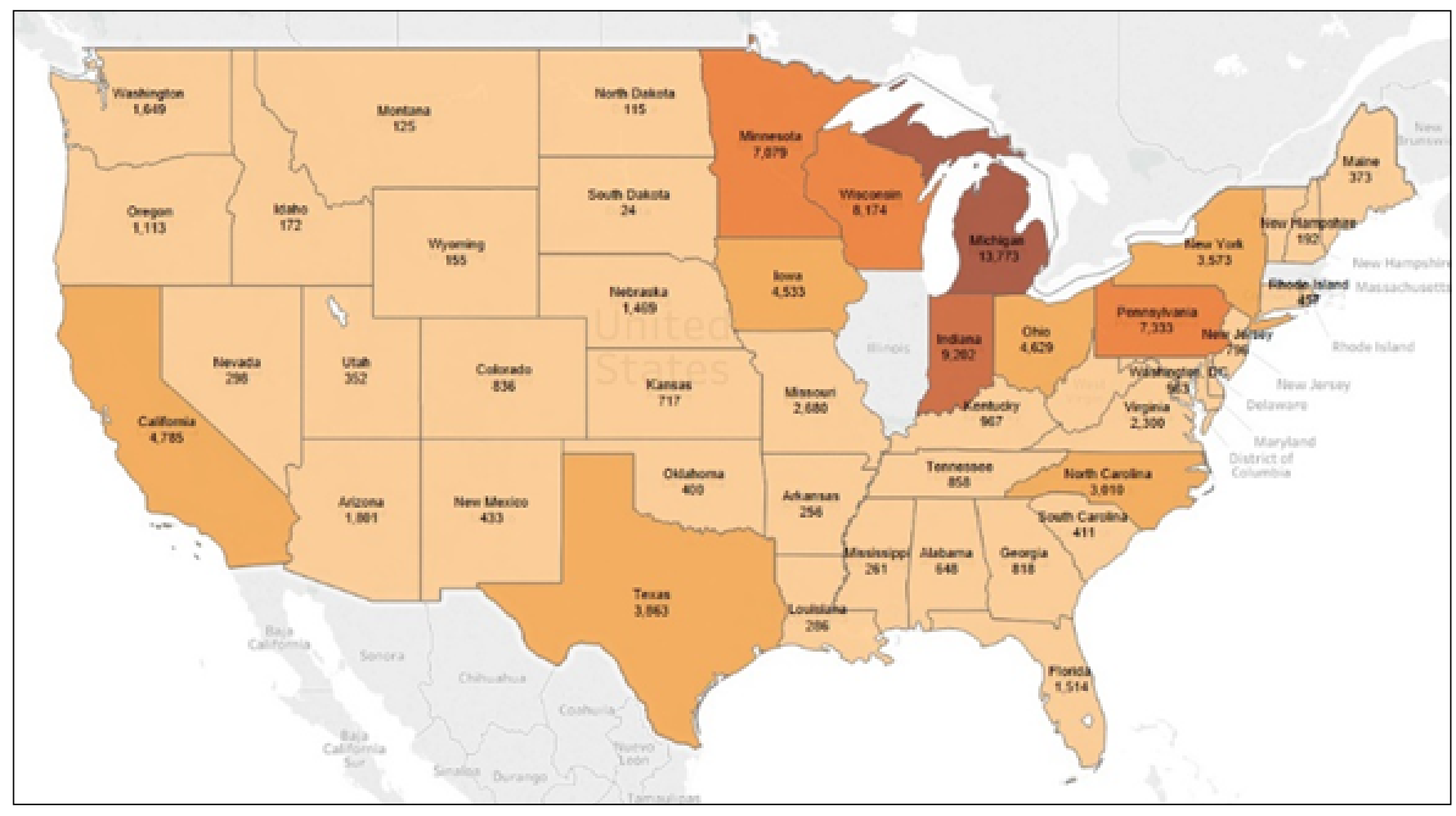

Figure 2. ILL Lending Map United States

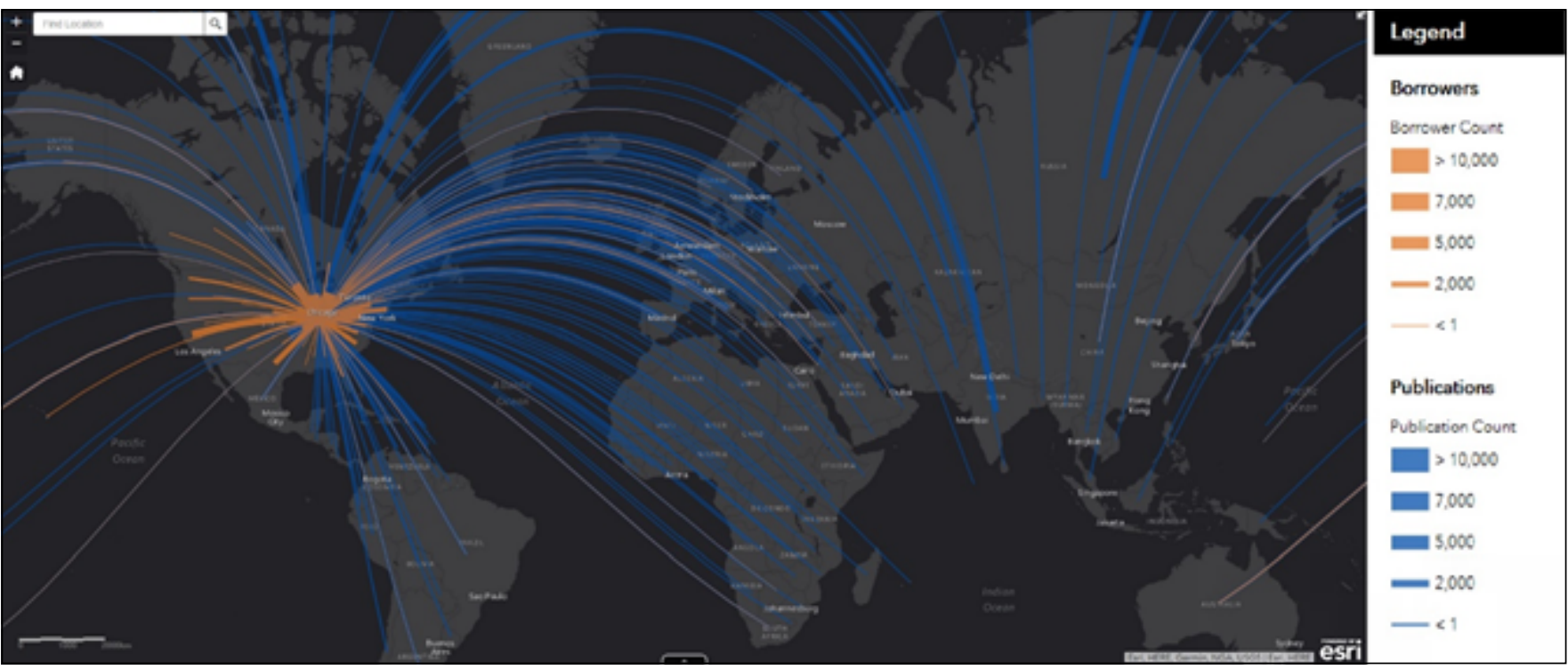

Figure 3. ILL Lending and Imprint Country

they are being used locally. It seems unlikely that this would be the case, but a future study that investigates denied ILL requests for area studies materials might be meaningful.

Second, it shows that while collaborative collecting is valuable, justification remains for multiple copies of the most popular publications to be held by collaborating institutions as these are the most in demand for both ILL and local use. It is likely that when materials reach a certain threshold of popularity, ILL helps meet the demand when local copies are checked out or otherwise unavailable for circulation. 


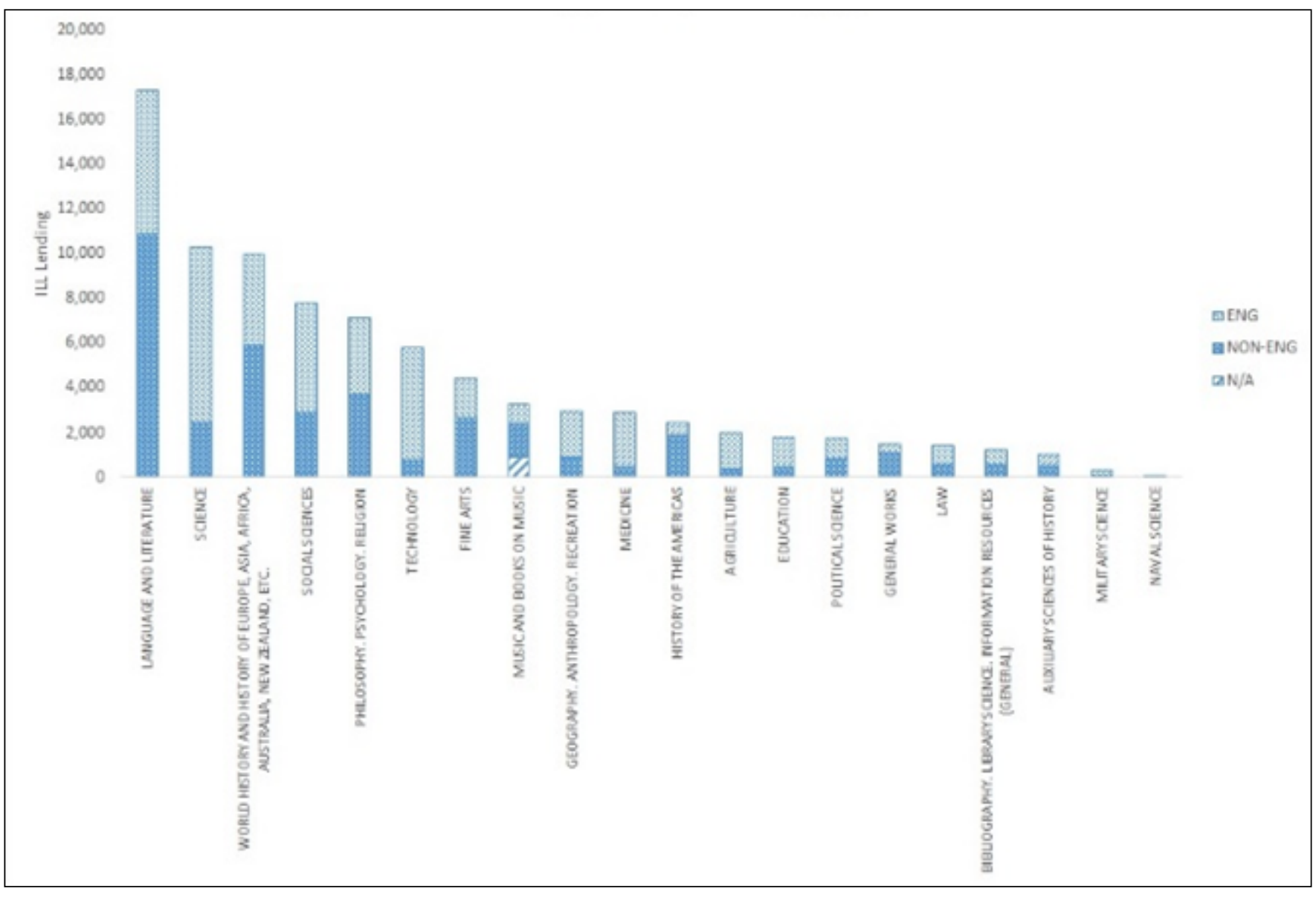

Figure 4. ILL Lending by LC Subject and Language

It is the middle range between the most rarely held and most commonly held materials that might prove to be the best place to seek opportunities for collaboration. These items experience the least demand both locally and externally. These observations provide further confirmation of the results of two papers cited in this study-O'Neill and Gammon and Wiley et al. A further analysis of which publishers, subjects, or languages tend to occupy these middle categories, particularly those items with between fifty-one and ninety OCLC holdings, might allow for targeted collaboration within regional consortia, as limiting further acquisitions in categories with combined factors of low demand and high relative-acquisition rates could lead to more effective resource use.

\section{Long-Tail Collections}

A total of 73,194 items, or 88.5 percent of all ILL monograph lending during the study period, were lent once during the five-year time period included in the data set. This single loan includes the ILL transaction for both US and foreign imprints. The University of Illinois lent 7,327 monographs twice via ILL, accounting for 8.9 percent of lending. Adding monographs lent via ILL three times during a five-year period brings the total percentage to over 99 percent, meaning that materials lent via ILL four or more times over a five-year period accounted for less than 1 percent $(<1$ percent) of overall ILL lending. In table 6 , the authors included only monographs as the aforementioned problems with journal volume information created misleading results about the relative importance of single volumes. However, less than 1 percent of the monographic volumes requested via ILL were circulated more than three times during a five-year period.

Filtering out US imprints scarcely changes the results. Of 46,612 monographs with non-US imprints, the university lent 41,506 monographs once, accounting for 89 percent of the total number of non-US imprint monographs lent via ILL. A total of 3,978, or 8.5 percent of the total, were lent twice.

When the data is further limited to titles held by five or fewer institutions, 5,040 items were lent just once, 552 
Table 5. ILL Lending and Local Circulation by the Number of OCLC Holdings

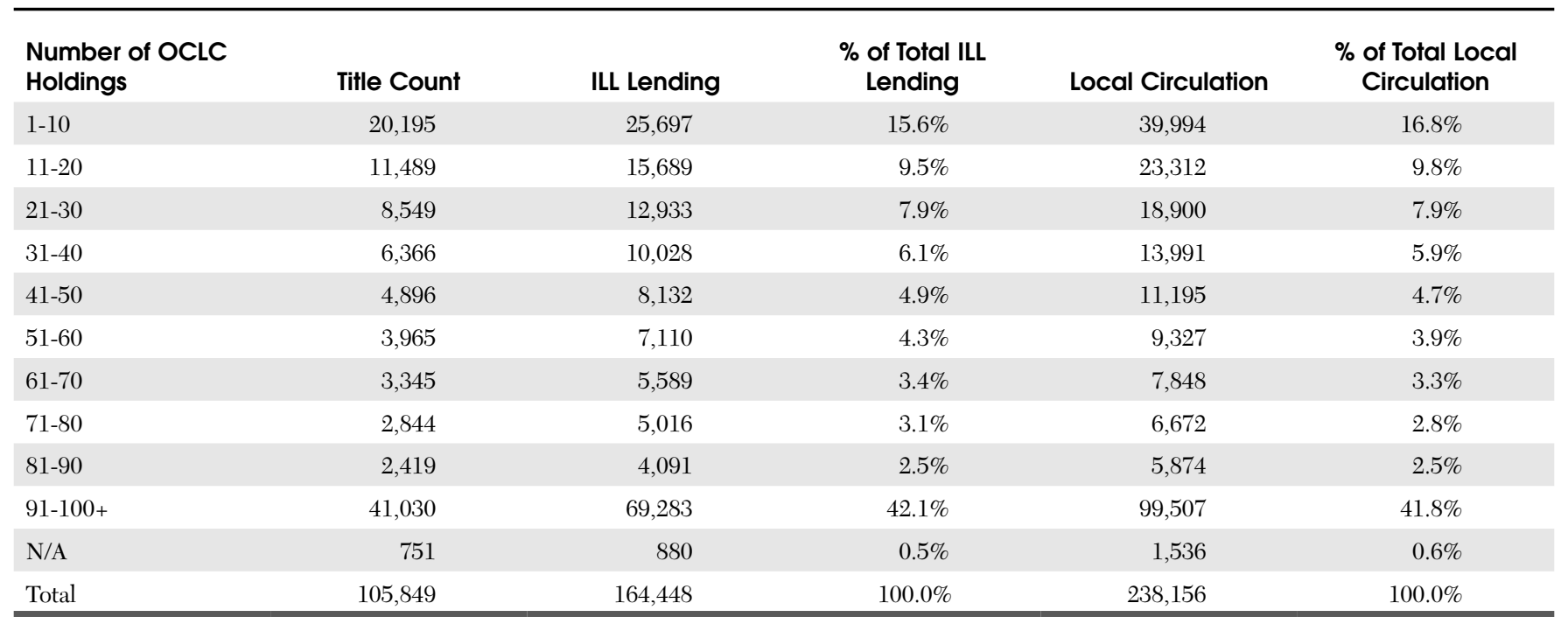

items lent twice, and 99 items lent three times over a fiveyear period. While the raw numbers of items lent via ILL changes depending on which filters are applied, the proportions remain strikingly close. More importantly, since the vast majority of monographs are lent via ILL once, this indicates that competing external demands for use of a single item are minimal. The evidence further substantiates this claim when juxtaposing the ILL statistics of a particular item against the local circulation for that same item. As demonstrated in table 6 , those monographs lent via ILL and locally circulated up to twelve times account for 99.1 percent of the total ILL monograph lending in this sample set, meaning that most of the volumes lent in this sample set appear to be sufficient to serve both local needs and the ILL borrowing demands placed upon them.

\section{Conclusion}

As research libraries make the transition from being collection-centric to increasingly service-centric organizations, a recurring challenge that remains is determining how institutions meet the needs of their local community. For many years, institutional leadership recognized the impossibility of collecting everything and the fact that fulfilling local needs often required accepting a level of dependency upon partner institutions. In this environment, institutions constructed cooperative collection development schemes, shared reference models, and brick-andmortar facilities to house and service lower-use collections. Yet, research libraries continue to face resistance from their local communities and, in some cases their own personnel, to adopting models that shift from locally held collections and toward an increased reliance upon the holdings of others.

The roots of these concerns vary from institutional mission and historical pride in local collections to concerns about access and efficient delivery of materials to concerns about the potential impact on research services that remain tied to serving local scholarly communities and institutional objectives, both of which may shift over time. However, the fact remains that locally held collections often serve populations at a distance, and local populations often benefit from collections held by other institutions.

This paper examines the lending use data of a particular set of collections over a five-year period. It attempts to determine whether arguments that categories of library material could serve broader communities and that more systematic cooperative collecting activities could result in a collection sufficient to serve a broader community is true. If truth remains in these arguments, it also stands to reason that this paper implicitly argues that deeper cooperative collection development activities that avoid unnecessary redundancy could free resources, allowing specialists to collect more deeply and institutions to better fulfill our collective service missions.

The greatest obstacle faced in implementing these models is that they challenge some established norms. Yet challenges to established norms that were met with concern in recent memory are increasingly viewed as challenges to our institutions to realize their potential. For example, the idea of digitizing the corpus of any one research library was as much fantasy fifteen years ago as the belief that the digitized corpus would reside in one digital repository or that users could create their own virtual collections within that repository. The motivation 
Table 6. ILL Lending and Local Circulation

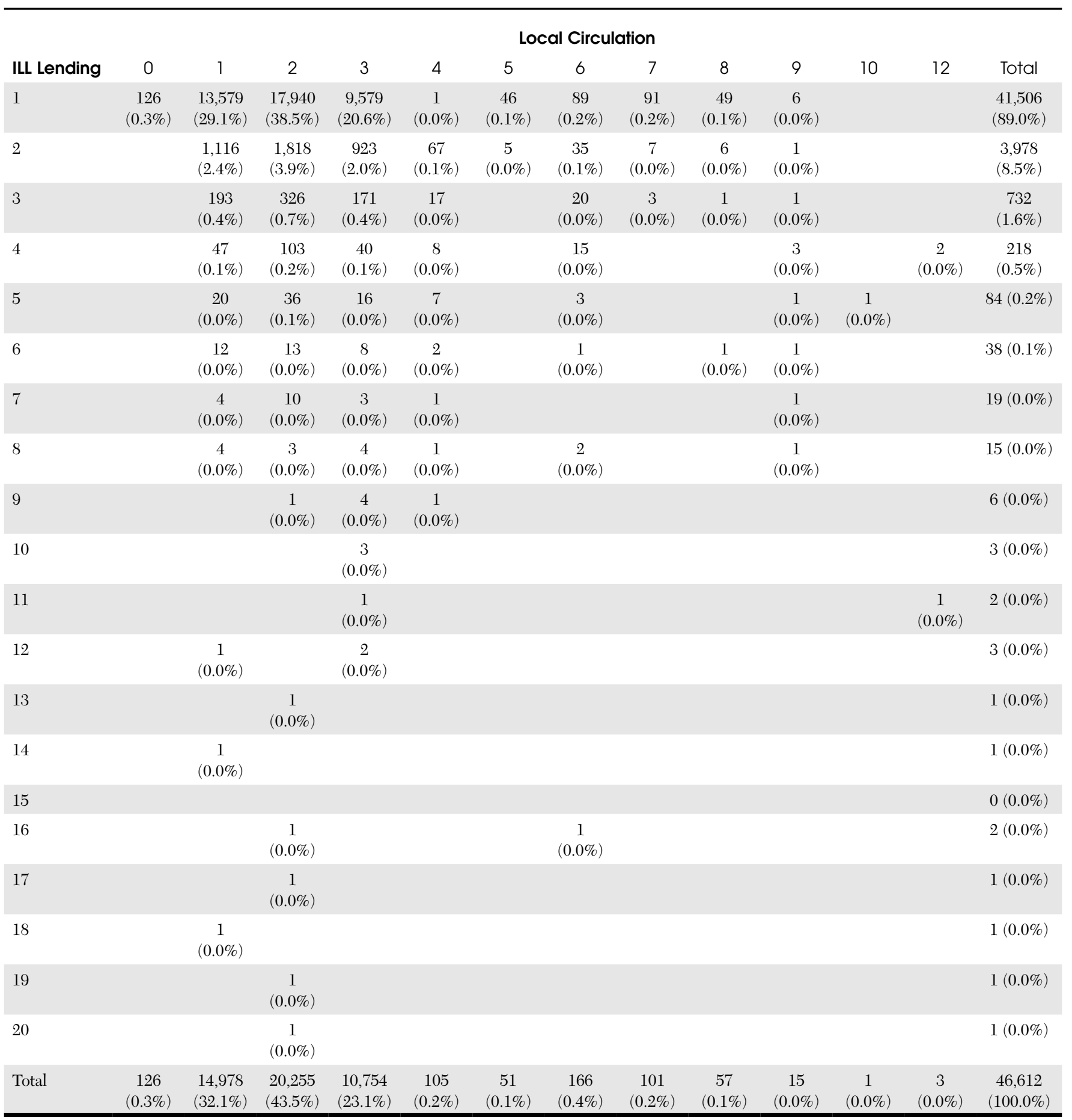

for libraries to collaborate-and achieve-by developing economies of scale is mounting.

As the data included in this study illustrates, the potential exists for collections of low-use materials to serve broad scholarly communities through resource sharing. However, looking at them as part of a broad network that serves scholarship could lead to far-reaching collection management and development decisions in which overlapping holdings are limited to the most used materials, and resources currently used to acquire those that might be classified as "moderately widely held" would be used instead to extend the long tail of acquisitions. This would further both our 
collective service mission and our mission to preserve our own heritage.

Extending the argument, could consortia establish hubs that would acquire, provide access, and preserve materials that are collectively purchased and legally held on behalf of their members? If yes, could collection development for such a hub be coordinated enough among the members to avoid unnecessary redundancy and effectively provide ondemand delivery to users throughout the network? As demonstrated by the coordinated efforts already explored by other groups of institutions, such a model is not beyond our reach and would have significant implications for individual institutions, regarding the nature of prospective collection development, the management of existing collections, and the ability of participating members to collect resources in a more systematic manner.

This study and the efforts undertaken by consortia thus far raise many questions that require further research. A study that examined the lending and borrowing patterns across a consortia of major academic research institutions could confirm whether those items identified by this study as being potential areas for establishing cooperative collecting arrangements are also viable areas for collaboration at other institutions. While all the borrowing in this study was accomplished with established lending models, the development of effective discovery-to-delivery methods will open further research possibilities. There are also policy implications of cooperative arrangements that need further examination. How do we meaningfully define differences in collaborative collecting policies for items held within "general collections" versus those collected as artifacts? If we collect fewer items in the middle tier of current holdings, does that substantively change the relative populations of "general" and "special" collections? Although alluded to earlier in this paper, the other significant research area requiring further exploration is how the collective collection serves as a preservation tool. What are the impacts of such models on our long-standing notions of institutional and collective stewardship?

As questions of deduplication against a collective holding are considered, what will constitute "true" duplication across the collective collection? There are many opportunities for libraries to work collaboratively to accomplish tasks that they could not accomplish individually and many opportunities for them to achieve efficiencies. During times of economic pressure, it is even more important for libraries to assume a pragmatic view towards innovative collaborative models of collection management. The recent successes of HathiTrust, the BioDiversity Heritage Library, the Digital Public Library of America, and mass digitization efforts argue for this approach. While all may not endure, the impact of these initiatives upon our communities is significant. The impact of long-standing programs, such as that inherent in CRL's cooperative collection development and preservation operations, further emphasizes that cooperative work can affect positive change on the community.

Perhaps the area that has longest frustrated the academic library community in terms of meeting local needs through cooperative effort has been prospective cooperative collection development. Opportunities exist, and the data in this paper and others support assertions that collections can support broad communities of scholars, that there is room for institutions to rethink collection development activities to identify resources that could support deeper collection development in targeted areas, and that research libraries can achieve efficiencies by collecting "at scale."

\section{References}

1. Michael Levine-Clark, "Access to Everything: Building the Future Academic Library Collection," portal: Libraries and the Academy 14, no. 3 (2014): 425-37, https://doi .org/10.1353/pla.2014.0015.

2. Brenda Bailey-Hainer et al.,"Rethinking Library Resource Sharing: New Models for Collaboration," Interlending \& Document Supply 42, no. 1 (2014): 7-12, https://doi.org /10.1108/ILDS-12-2013-0038; Levine-Clark, "Access to Everything," 425-37; Scott Walter and Paula T. Kaufman, "Service is Sovereign: Strategic Change and the Future of Library Services" (presentation, Library Connect Seminar Tokyo, Japan; Singapore; Selangor Darul Ehsan, Malaysia; and Bangkok, Thailand, 2008), accessed September 15, 2017, http://hdl.handle.net/2142/8769; Brian Lavoie, and Constance Malpas, Print Management at "Mega Scale": A Regional Perspective on Print Book Collections in North
America (Dublin, OH: OCLC Research, 2012), accessed June 5, 2017, www.oclc.org/content/dam/research/public ations/library/2012/2012-05.pdf; Thomas H. Teper et al., HathiTrust Print Monographs Archive Planning Task Force: Final Report (Ann Arbor, MI: HathiTrust, 2014), accessed June 5, 2017, http://hdl.handle.net/2142/78147.

3. Kimberly L. Armstrong and Thomas H. Teper, "Library Consortia and the CIC: Leveraging Scale for Collaborative Success," Serials Review 43, no. 1 (201): 28-33, https://doi .org/10.1080/00987913.2017.1284493.

4. Center for Research Libraries, "History of CRL," accessed May 15, 2017, www.crl.edu/about/history.

5. Joe Lenkart et al., "Measuring and Sustaining the Impact of Less Commonly Taught Language Collections in a Research Library," College \& Research Libraries 76, no. 2 (2015): 222-33, https://doi.org/10.5860/crl.76.2.222. 
6. Ohio State University, “2013 National Resource Centers Conference: Demonstrating the Impact of National Resource Centers," accessed June 5, 2017, https://easc.osu .edu/sites/easc.osu.edu/files/conference-2013-nrc-tentative -schedule.pdf; Indiana University at Bloomington, "Collaboration, Advocacy, and Recruitment: Area and International Studies Librarianship Workshop," accessed May 15, 2017, www.indiana.edu/ libarea/main.html; University of Texas at Austin, "International and Area Studies Collections in the 21st Century (IASC21)—2014 Workshop," accessed June 5, 2017, http://conferences.lib.utexas.edu/iasc21/.

7. Collete Mak, "Resource Sharing Among ARL Libraries in the US: 35 Years of Growth," Interlending \& Document Supply 39, no. 1 (2011): 26-31.

8. Bonnie Juergens and Tim Prather, "The Resource Sharing Component of Access," Journal of Library Administration 20, no. 1 (1995): 77-94.

9. Ibid.

10. Deborah Lynn Jakubs, "Trust Me: The Keys to Success in Cooperative Collections Ventures," Library Management 36, nos. 8-9 (2015): 653-62, https://doi.org/10.1108/LM-08 $-2015-0058$.

11. Ibid., 657.

12. Mary E. Jackson et al., Changing Global Book Collection Patterns in ARL Libraries (Washington, DC: Association of Research Libraries, 2006).

13. Joseph A. Williams and David E. Woolwine, "Interlibrary Loan in the United States: An Analysis of Academic Libraries in a Digital Age," Journal of Interlibrary Loan, Document Delivery \& Electronic Reserve 21, no. 4 (2011): 165-83, https://doi.org/10.1080/1072303X.2011.602945.

14. Edward T. O’Neill and Julia A. Gammon, "Building Collections Cooperatively: Analysis of Collection Use in the OhioLink Library," in Pushing the Edge: Explore, Engage, ed. Dawn Mueller (Chicago: Association of College and Research Libraries, 2009), 36-45.

15. Ibid.

16. Lynn Wiley, Tina E. Chrzastowski, and Stephanie Baker, "A
Domestic Monograph Collection Assessment in Illinois Academic Libraries: What Are We Buying and How Is It Used?, Interlending \& Document Supply 39, no. 4 (2011): 167-75, https://doi.org/10.1108/02641611111187587.

17. Dan C. Hazen and James Henry Spohrer, Building Area Studies Collections (Wiesbaden: Harrassowitz-Verlag, 2007).

18. Robert Davis, "2CUL Slavic: The View So Far," Slavic \& East European Information Resources 18, no. 1-2 (2017): 67-73, https://doi.org/10.1080/15228886.2017.1322383.

19. Andrew Leykam, "Exploring Interlibrary Loan Usage Patterns and Liaison Activities: The Experience at a US University," Interlending \& Document Supply 36, no. 4 (2008): 218-14, https://doi.org/10.1108/02641610810919570.

20. Ibid.

21. International Federation of Library Associations and Institutions, "National Bibliographic Register," accessed May 15, 2017, www.ifla.org/node/2216.

22. International Publishers Association, "Annual Report October 2014-October 2015," accessed May 15, 2017, www .internationalpublishers.org/images/annualreports/ipa_ar _online.pdf.

23. Philip G. Altbach, "Publishing in National Languages: What Africa Could Learn from Other Continents," Logos 10, no. 2 (1999): 75-80, https://doi.org/10.2959/logo.1999.10.2.75. German Book Office New Delhi, "Perspectives on Publishing in India 2014-2015. Trends in Indian Publishing: An Overview of the Current Trends and Opportunities in the Indian Publishing Market," accessed August 20, 2018, https://dokumen.tips/documents/india-book-market -2014-2015.html.

24. Online Computer Library Center, "Directory of OCLC Members," acessed June 5, 2017, www.oclc.org/en/contacts /libraries.html.

25. Esra Çeltek Coşkun et al., University of Illinois at UrbanaChampaign ILL Lending and Circulation Data, 2009-2013, (August 31, 2018), distributed by Illinois Data Bank, https:// doi.org/10.13012/B2IDB-6701059_V1. 